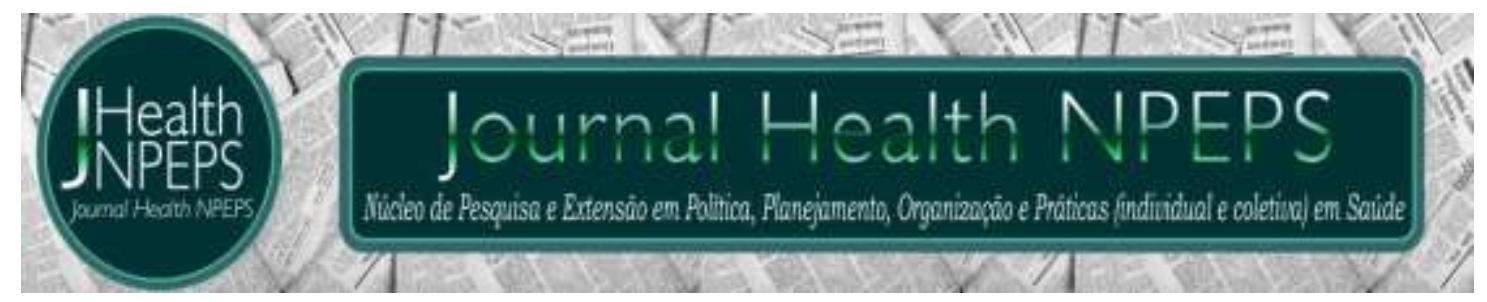

http://dx.doi.org/10.30681/252610103716

EDITORIAL

\title{
Reflexões sobre o histórico e caminhos da interdisciplinaridade na educação superior no Brasil
}

\section{Reflections on the history and paths of interdisciplinarity in higher education in Brazil}

\section{Reflexiones sobre el histórico y caminos de la interdisciplinariedad en la educación superior en Brasil}

\section{Marcos Vinícius Ferreira Vilela ${ }^{1}$}

Nas ultimas décadas, a interdisciplinaridade atraiu atenção significativa nas produções e discussões acadêmicas, bem como, nas legislações e políticas que regem os sistemas de ensino. Entretanto, podemos afirmar que o conceito em torno da interdisciplinaridade está longe de ser unívoco. Estudiosos sobre o tema, como Ivani Fazenda, nos alertam que o uso indiscriminado desse termo ou conceito, tem se tornado um certo modismo. Tal fato, implica no crescimento de ações e projetos que se autodenominam interdisciplinares. Todavia, a maioria destes trabalhos está distante do que realmente se espera de uma prática interdisciplinar.

O movimento interdisciplinar surgiu na Europa em meados de 1960. Segundo Francischett ${ }^{1}$, dentre os esforços realizados por Gusdorf e outros adeptos desse movimento, almejava-se "a tentativa de elucidação e de classificação temática das propostas educacionais como compromisso de

\footnotetext{
${ }^{1}$ Licenciado em Biologia e Bacharel em Direito. Mestre em Ecologia e Evolução e Doutor em Educação em Ciências e Matemática. Professor do Instituto Federal de Mato Grosso (IFMT) - Campus Rondonópolis. E-mail: marcos.vilela@roo.ifmt.edu.br ORCID ID: https://orcid.org/0000-0001-8437-7646
} 
alguns professores universitários que procuravam romper a 'Educação por migalhas".

Nesse período, o movimento interdisciplinar ganhou força, sobretudo na França e na Itália, impulsionado por grupos estudantis que exigiam à época um novo estatuto de universidade e escola. Em suma, buscava-se constituir uma oposição ao saber alienado da época, sendo atribuída a Jean Piajet a criação do termo "interdisciplinaridade"2.

Por volta de 1960, aconteceram importantes eventos e ações em prol da consolidação do movimento interdisciplinar. Como grande mobilizador da causa, tivemos Georges Gusdorf. No ano de 1961, Gusdorf submeteu a UNESCO, um projeto de investigação interdisciplinar voltado às Ciências Humanas. Em torno desse projeto, circundava o objetivo de constituir um grupo de notáveis da área para discutirem o tema ${ }^{3,4}$.

A partir do encontro desses especialistas e de suas produções conjuntas, as discussões sobre interdisciplinaridade passam a ter repercussão internacional. Em 1970, é realizado um Seminário sobre Pluridisciplinaridade e Interdisciplinaridade nas Universidades. Dentre os especialistas presentes, destacamos novamente Jean Piaget, que em sua fala tratou da necessidade de se buscar um arranjo comum para as disciplinas, como forma de evitar a visão compartimentada da realidade ${ }^{5}$.

No Brasil, as discussões sobre Interdisciplinaridade surgem em meados das décadas de 1960 e 1970. O precursor desse tema no país foi Hilton Japiassu (orientado de Gusdorf), por meio de sua obra Interdisciplinaridade $e$ Patologia do Saber. Mais tarde, ressaltamos as contribuições de Ivani Fazenda, por meio de suas pesquisas e produções na área, sobretudo no âmbito do GEPI ${ }^{4}$.

As concepções de interdisciplinaridade defendidas por Japiassu e Ivani Fazenda, tem como ponto em comum, a superação da fragmentação do conhecimento, por meio da restauração de um saber unificado. Nesse sentido, Japiassu $^{6}$ ao buscar representar o seu pensamento acerca da fragmentação do conhecimento, compara o surgimento exacerbado de disciplinas científicas, à verdadeiras “cancerizações epistemológicas”. 
As concepções de interdisciplinaridade, predominantes na França e também difundidas Hilton Japiassu e Ivani Fazenda, tem orientado de forma hegemônica, as teorizações sobre esse tema no Brasil. Entretanto, com base nas reflexões de Jantsch \& Bianchetti, as concepções de interdisciplinaridade defendidas por esses estudiosos, tendem a estabeler que o trabalho em parceria (disciplinas e seus especialistas), o diálogo e a atitude frente à fragmentação do conhecimento, são elementos suficientes para a ocorrência de um trabalho interidiscplinar.

Em discordância às concepções elencadas acima, nossa argumentação é fundamentada pelo fato de que a mera vontade dos sujeitos em realizar interdisciplinaridade, não é o suficiente para que esta ocorra. Há de se considerar que um trabalho interdisciplinar deve considerar o processo histórico da construção dos saberes, aos quais pretende-se articular. Além disso, é importante compreender que tanto a fragmentação do conhecimento, quanto o próprio movimento em torno da interdisciplinaridade, estão diretamente ligados aos sistemas de produção e do trabalho, vigentes em cada momento histórico.

Estudiosos como Santomé ${ }^{5}$, corroboram com essa linha de pensamento, ao afirmar que o processo de fragmentação do conhecimento, caminha lado a lado com o processo de fragmentação do trabalho, sobretudo nas indústrias. Tal afirmação pode ser melhor contextualizada, ao relembrarmos do fordismo e do taylorismo, concepções relacionadas a divisão do trabalho e o modo de produção das indústrias, respectivamente, que foram marcantes no início do século $X X$.

Além disso, entendemos que nem todas as disciplinas e especializações, surgiram em decorrência da fragmentação de um conhecimento único. Dessa forma, se há pontos em comum (saberes e metodologias) entre as diversas especializações, não podemos considerar essas “interseções disciplinares" como evidências, de que um dia estas integraram um corpo único de conhecimento, mas sim, como possibilidades de interação entre elas, tornando a interdisciplinaridade possível.

Destarte, consideramos que não há de se lamentar pela perda de um conhecimento globalizante, que em tese, teria sido "ferozmente" 
fragmentado pelo surgimento de novas especializações. Além disso, entendemos que para que haja a interdisciplinaridade, seja na ciência ou no ensino, é fundamental a contribuição de um corpo especializado de disciplinas, que por meio da interação de seus conhecimentos e métodos, propiciará o enfrentamento e/ou a compreensão de temas ou problemas complexos.

Conforme citamos anteriormente, o movimento em prol da interdisciplinaridade, ganha repercussão internacional, sobretudo quando a sua discussão adentra o meio acadêmico. A UNESCO, juntamente com a OCDE, publicaram na década de 1970, um relatório que foi fruto de importantes discussões realizadas no âmbito de um seminário internacional promovido pela CERI. Neste evento, o cerne das discussões, se concentrou em discutir as perspectivas de interdisciplinaridade nas universidades.

Todavia, a discussão em torno do trabalho interdisciplinar nas universidades europeias, sobretudo na França, despertou uma forte resistência por uma parte da comunidade acadêmica. Na visão desses segmentos, a mudança para um paradigma interdisciplinar, poderia colocar em risco a organização acadêmica tradicional, que levou séculos para se consolidar. Além disso, tais mudanças poderiam alterar profundamente as relações de poder nas Instituições.

No Brasil, a discussão sobre a interdisciplinaridade nas universidades ocorreu de uma forma mais tardia, sendo os debates impulsionados pela própria comunidade acadêmica ${ }^{7}$. Esse movimento interdisciplinar tem ocorrido de forma gradativa nos últimos 40 anos, tendo seu início no âmbito dos Programas de Pós-graduação.

Entre as décadas de 1970 a 1990, a implementação de cursos de pósgraduação com formato interdisciplinar, se deu de maneira isolada em algumas universidades. Todavia, o reconhecimento e a institucionalização dessas formações interdisciplinares se deram apenas no início do século XXI. Nesse processo de consolidação, a CAPES assume um importante protagonismo, inicialmente com a criação de um comitê multidisciplinar, e mais adiante com a sua conversão para um comitê de avaliação da área interdisciplinar.

A partir da institucionalização no âmbito da CAPES de comitês especializados na avaliação de propostas de cursos interdisciplinares, a 
criação de programas de pós-graduação nesse formato cresceu de forma acelerada. Dentre as áreas mais contempladas por esses cursos interdisciplinares, destaca-se a área ambiental. Nessa lógica, em determinados temas como o meio ambiente, o avanço das pesquisas dependem do trabalho colaborativo entre pesquisadores e especialidades distintas ${ }^{7}$.

A chegada da interdisciplinaridade nos cursos de graduação ocorreu apenas após a sua consolidação na pós-graduação. 0 pensamento interdisciplinar que agora busca se instalar na graduação, visa readequar a universidade e seus cursos a um novo estatuto do conhecimento científico. Os problemas complexos da humanidade, bem como, as necessidades do sistema de produção vigente, não mais conseguem ser resolvidos e atendidos a partir de uma leitura de mundo, tendo como sustentáculo o modelo disciplinar.

Nesse aspecto, urge a necessidade de se repensar sobre o papel da universidade frente a uma nova sociedade do conhecimento. Vale ressaltar que ao longo das ultimas décadas, vários movimentos que almejam a reconstrução e ressignificação da universidade, têm se dedicado a apontar caminhos para essa reestruturação. Movimentos como a Universidade Nova que se sustenta a partir das convicções de Anísio Teixeira, a Declaração de Bolonha na Europa e mais recentemente o REUNI, são iniciativas que visam a concepção de um novo modelo de universidade.

O REUNI foi um programa do governo federal instituído no ano de 2007, que teve por objetivo promover a expansão da oferta de vagas na educação superior, bem como, conceder melhores condições de acesso e permanência na universidade. Além disso, buscava garantir condições para a reestruturação das universidades, frente as novas demandas do século XXI.

Nesse sentido, foram criados novos cursos e novas universidades, sendo incentivado a criação de uma estrutura organizacional universitária e curricular, que privilegiassem a interdisciplinaridade e a flexibilização. Nessa perspectiva, almejava-se a substituição de uma estrutura baseada em departamentos e faculdades, por estruturas organizacionais que pudessem fomentar um maior diálogo e interação entre as diferentes áreas do conhecimento e seus especialistas. 
Dentre as Universidades criadas nesse período e que adotaram esse novo modelo de organização acadêmica, podemos citar como exemplos, a UFABC, a UFOPA e a UFSB. Nessas instituições, além dessa nova configuração organizacional, foram também implantados cursos de graduação em um formato interdisciplinar, denominados de "Bacharelados Interdisciplinares (Bls)".

Os Bls são cursos que se constituem a partir da inserção de metodologias interdisciplinares, sendo este novo modelo educacional composto por ciclos de formação. No primeiro ciclo, o acadêmico ingressa na universidade e obtém uma formação básica em uma grande área do conhecimento, podendo ser: Artes, Humanidades, Ciência e Tecnologia, Saúde, etc. Esse primeiro ciclo tem duração de três anos, sendo que ao final deste, o aluno obtém o título de bacharel na respectiva área de conhecimento. Após o final desse ciclo, o aluno pode escolher uma área específica para a profissão que deseja cursar ou optar por adentrar no mercado de trabalho.

Esses novos cursos, com foco na formação por área do conhecimento, foram implantados nas novas universidades e em outras diversas que foram subsidiadas por recursos oriundos do REUNI. A implantação desses cursos tratava-se de uma exigência do referido programa, onde as universidades que recebessem recursos, deveriam promover a remodelação dos currículos dos cursos, em torno de metodologias interdisciplinares. A partir desses novos currículos, buscava-se promover a autonomia dos estudantes, durante o seu percurso formativo na universidade.

Nessa nova perspectiva de formação, a universidade não deveria se preocupar apenas com a formação de recursos humanos (especialistas), com vistas a atender o mercado de trabalho. A missão desses novos cursos e da própria universidade, também deveria se voltar à formação de cidadãos críticos, que pudessem ser capazes de contribuir com a resolução de problemas complexos da realidade brasileira.

Além das universidades e cursos criados em decorrência do REUNI, destaca-se a criação também nesse mesmo período, dos Institutos Federais de Educação, Ciência e Tecnologia (IFs). Os IFs são instituições pluricurriculares e multicampi, que se dedicam a oferta de cursos técnicos (integrados ao ensino 
médio e subsequentes), cursos de graduação (tecnólogos, bacharelados e licenciaturas) e pós-graduação, que sejam capazes de contribuir com a formação e o desenvolvimento das localidades em que estão inseridos.

Especificamente no caso das licenciaturas, os IFs têm por força de lei, a obrigatoriedade de ofertar $20 \%$ (vinte por cento) de suas vagas para cursos de formação de professores. Dentre as áreas de formação a serem atendidas por esses cursos, a legislação prepondera que estes sejam ofertados sobretudo na área de Ciências da Natureza e Matemática.

Nessa perspectiva, diversos IFs tem ofertado cursos de licenciatura, que se dedicam a formar professores por área do conhecimento, em uma perspectiva interdisciplinar. Dentre os cursos ofertados, destacamos as Licenciaturas interdisciplinares em Ciências Naturais. Esses cursos têm por objetivo formar professores para essa área de conhecimento, com vistas a atuar na educação básica. Entendemos que tais propostas de formação, corroboram com o que dispõe a nova BNCC. Conforme previsto nessa nova base curricular, os conteúdos a serem ensinados na educação básica, deverão romper com o modelo de ensino disciplinar, com vistas a uma maior integração dos conteúdos específicos, dentro de uma grande área do conhecimento.

Entende-se que o foco principal dessa nova reorganização dos cursos e das instituições, em torno de uma proposta de trabalho interdisciplinar, busca um realinhamento da academia, com as novas necessidades da sociedade e do mundo do trabalho. Nesse segmento, é papel dessas Instituições e de seus cursos formar profissionais e cidadãos mais dinâmicos, versáteis e capazes de enxergar e enfrentar os dilemas da realidade, de uma forma mais crítica, participativa e colaborativa.

Todavia, é importante também compreender, que a perspectiva da implantação da interdisciplinaridade na graduação, deverá enfrentar maiores obstáculos, do que aqueles observados no momento de sua chegada à pósgraduação. Apesar de todas as críticas e o visível esgotamento do modelo de formação disciplinar, há de concordarmos que este teve a sua contribuição e ainda está muito presente nos cursos ofertados pelas Instituições de ensino superior. 
Além disso, tem-se que considerar que apesar da motivação altruísta de ser formar um cidadão mais crítico e versátil, o mercado de trabalho será a instância que deverá absorver esses profissionais, logo após a sua formação universitária. Nesse segmento, autores ${ }^{7,8}$ ressaltam que ainda é cedo para se estabelecer um prognóstico de como o mercado, os gestores, o poder público e a sociedade em geral, vão reagir em relação a esses novos profissionais.

No que se diz respeito às licenciaturas Interdisciplinares, em especial aquelas voltadas à formação para a área de Ciências Naturais, os profissionais oriundos desses cursos, têm encontrado dificuldades para sua inserção profissional na rede pública de ensino. Segundo os autores, os concursos públicos voltados à contratação de professores para a disciplina de ciências, apesar do caráter integrador e interdisciplinar da disciplina, ainda optam por contratar professores formados em cursos com formato disciplinar ${ }^{9}$.

Outros aspectos referentes à legislação e a estrutura burocrática da educação superior no Brasil, também têm se configurado como obstáculos à implementação de cursos interdisciplinares. Quanto a legislação, destaca-se a inexistência de diretrizes e referenciais curriculares, que deveriam nortear a elaboração de currículos e projetos pedagógicos desses cursos. A ausência desses parâmetros legais, fazem com que os cursos existentes tenham estruturas muitos diversas entre si, o que tem prejudicado os cursos durante a sua avaliação pelo Ministério da Educação (MEC). Ressalta-se ainda que boa parte desses cursos, ainda não tem os seus alunos avaliados pelo ENADE.

Quanto aos aspectos burocráticos, ressalta-se o fato de que todos os sistemas de gerenciamento de processos da educação superior, bem como, os sistemas de gestão acadêmica das instituições, ainda se encontram estruturados para o acompanhamento e a gestão de cursos, com formato disciplinar. No caso específico do sistema e-MEC, não existe a possibilidade de inserção de currículos estruturados a partir de temas, modelo esse muito comum em cursos interdisciplinares. Dessa forma, se o currículo é organizado por temas, o sistema "entende" cada um destes como componente curricular (disciplina).

Devemos também considerar como um desafio à formação interdisciplinar na graduação, a formação disciplinar dos professores 
formadores. Nesse aspecto, quase que a totalidade dos professores universitários, são oriundos de cursos de graduação e pós-graduação, estabelecidos em um formato disciplinar. Dessa forma, cabe as Instituições de ensino ofertar formação adequada aos professores, e estes, estarem dispostos a sair da zona de conforto de suas disciplinas, para se dedicarem a realizar trabalhos colaborativos e interdisciplinares.

Apesar dos desafios postos acima, e outros mais que possam aparecer, as barreiras que segregam o conhecimento em compartimentos estanques, vêm se reduzindo gradativamente ${ }^{7}$. Diante dos problemas complexos a serem enfrentados pela humanidade, cada vez mais os especialistas se veem impelidos a dialogar e trabalhar colaborativamente com outros saberes e especialistas.

Finalmente, diante do cenário apresentado, cabe as Instituições de Educação Superior, garantir e fomentar o diálogo entre as disciplinas e seus especialistas. Além disso, torna-se necessário um aprofundamento das discussões acerca das diferentes concepções de interdisciplinaridade. A clara compreensão de que a interdisciplinaridade não se trata de uma mera justaposição de disciplinas e está plenamente articulada ao processo histórico da produção do conhecimento, são fundamentais para se evitar que um promissor trabalho interdisciplinar não recaia em um simples modismo.

\section{REFERÊNCIAS}

1. Francischett $M N$. $O$ entendimento da interdisciplinaridade no cotidiano. Covilhã Biblioteca on line de Ciências da Comunicação, 2005. Disponível em: <http://www.bocc.ubi.pt/pag/francishett-mafalda-entendimentoda-interdisciplinaridade.pdf>. Acesso em: 11 maio. 2018

2. Mozena ER, Ostermann F. A interdisciplinaridade na legislação educacional, no discurso acadêmico e na prática escolar do ensino médio: panaceia ou falácia educacional? Cad bras ensino fís. 2016; 33(1):92-110.

3. Minayo MC. DE S. Interdisciplinaridade: Funcionalidade ou utopia? Saúde soc. 1994; 3(2):42-64.

4. Silva LVL. Interdisciplinaridade: Conceito, História e Obstáculos para sua 
Implementação na Escola. Cad cult ciênc. 2008; 3(1):1-17.

5. Santomé JT. Globalização e interdisciplinaridade: o currículo integrado. Porto Alegre: Artmed; 1998.

6. Japiassu H. Interdisciplinaridade e Patologia do Saber. Rio de Janeiro/RJ: Imago; 1976.

7. Pereira EQ, Nascimento EP. A interdisciplinaridade nas universidades brasileiras: trajetória e desafios. REDES. 2016; 21(1):209-232.

8. Veras RM, Lemos DVS, Macebo BTF. A trajetória da criação dos bacharelados interdisciplinares na Universidade Federal da Bahia. Rev Aval Educ Sup. 2015; 20(3):621-641.

9. Vilela MVF, Barth A, Gomes MDN. O lugar do licenciado em Ciências Naturais/da Natureza na educação básica brasileira: uma análise a partir dos editais de concursos públicos. Rev prat doc. 2017; 2(1):48-61. 